Trabajos y Comunicaciones, 2da. Época, Nº 45, e038, marzo 2017. ISSN 2346-8971

Universidad Nacional de La Plata.

Facultad de Humanidades y Ciencias de la Educación.

Departamento de Historia

\title{
Horacio Tarcus. El socialismo romántico en el Río de la Plata (1837-1852). Buenos Aires: Fondo de Cultura Económica, 2016, 382 páginas
}

\section{Martín González Dombrecht*}

* Universidad Nacional de Tres de Febrero (UNTREF), Argentina I gonzalezmartin1987@gmail.com

Desde hace tiempo, Horacio Tarcus es referencia ineludible en materia de estudio sobre las izquierdas en Argentina. El autor ha contribuido a la renovación, no sólo de este campo específico, sino también al de la historia intelectual en general, junto con autores como Elías Palti, Jorge Myers y Carlos Altamirano. Entre historia cultural e intelectual, su nueva obra se inserta en lo que este último ha denominado historia de las elites culturales.

El libro, que aborda la recepción del socialismo romántico en el Río de la Plata entre 1837 y 1852, constituye un estudio de caso sobre la difusión a nivel mundial de esta corriente de pensamiento durante la primera mitad del siglo XIX. Sin duda, se encuentra orientado por importantes preguntas: ¿fue posible leer las obras de los socialistas románticos en el Río de la Plata? Y si lo fue, ¿quiénes las leían? ¿Por qué? ¿Para qué? ¿Cómo las leían? En las antípodas de gran parte de la historiografía anterior, la hipótesis central de Tarcus es que el socialismo romántico no fue un mero fenómeno de importación, "fuera de lugar" y necesariamente pasajero. Por el contrario, las jóvenes elites intelectuales de ambos lados del río llevaron a cabo una resignificación de nociones y conceptos socialistas, y elaboraron a partir de ellos un lenguaje político propio que les permitió, a su vez, pensar y operar sobre la escena política rioplatense.

Los casos estudiados se encuentran hábilmente seleccionados, abundantemente documentados y, en su conjunto, brindan respaldo a la hipótesis central del libro. Tarcus logra identificar en los discursos y principios asociativos de los principales exponentes intelectuales rioplatenses la 
adopción de nociones saintsimonianas y mazzinianas, de Leroux y de Fourier. Aquellos jóvenes intelectuales de los '30 fueron los primeros en resaltar los efectos nocivos del individualismo y de proponer un programa democrático radical que comprendía la educación popular, la secularización, la emancipación de la mujer y el asociacionismo. Esteban Echeverría, Juan B. Alberdi, Marcos Sastre, Miguel Cané (p), Andrés Lamas, Domingo F. Sarmiento, sus asociaciones (el Salón Literario, la Joven Argentina) y sus principales periódicos y producciones literarias y filosóficas (como la Creencia social o el Fragmento Preliminar), son estudiados minuciosamente por Tarcus.

Pero el análisis no se detiene allí, sino que logra dar cuenta de los procesos de recepción y reelaboración del ideario socialista en territorio rioplatense. Por un lado, su estudio aporta sugerentes hipótesis respecto a la dificultad en la adopción de determinadas ideas socialistas debido a las condiciones políticas locales. Así, para el autor, la adhesión de la Generación del ’37 a los principios democráticos del socialismo se vio atenuada ya que, en consistencia con su evaluación historicista del presente político rioplatense, el gobierno de Rosas era la expresión lógica del estado del pueblo. Aquí se advierte la presencia de principios del liberalismo doctrinario antes que socialistas. Por el otro lado, Tarcus logra conectar de forma precisa la adopción de ciertas nociones con las necesidades políticas concretas de los actores: cuando en 1839, Alberdi abogaba por la intervención francesa, propuso una idea de Patria congruente con la noción de humanidad socialista: "la patria es la humanidad: el pueblo es el género humano”, dirá desde El Nacional.

La presencia del pensamiento socialista en la Banda Oriental, principalmente en su capital, Montevideo, no se explica, para Tarcus, únicamente por la emigración de los exiliados porteños luego de 1838. Con anterioridad, la ciudad se había convertido en un espacio de confluencia internacional de exiliados, y al mismo tiempo de rivalidad entre Francia e Inglaterra. Es así que, a partir de 1839, Montevideo ya contaba con una vigorosa vida política a la vez que cultural. En este contexto, Tarcus se aboca al estudio de dos personalidades poco conocidas por la historiografía argentina: Marcelino Pareja, un economista político preocupado por hacer coincidir el interés privado con el público, y Eugène Tandonnet, un furierista francés editor del periódico Le messager Française, de gran circulación en Montevideo, y no sólo entre la comunidad francesa allí instalada.

Sin duda, el tratamiento teórico-metodológico del libro merece ser consignado. En primer lugar, la problemática es abordada desde la “estética de la recepción”, por lo que el énfasis se encuentra puesto en el sujeto lector y la circulación de ideas, mientras que el texto y su contexto de producción ocupan un lugar periférico. La atención se dirige a la reconstrucción de la recepción del socialismo desde las representaciones activas, el bagaje cultural y los usos por parte de los actores sociales. En segundo lugar, el libro rompe con el tradicional tratamiento circunscripto a lo nacional y pone el acento en la circulación “internacional” de ideas: los actuales estados de Argentina, Uruguay y Brasil conformaban un "amplio espacio compartido”, de fronteras porosas y de fluidos intercambios, no sólo de bienes y personas, sino también de ideas provenientes de múltiples ámbitos de producción: de Francia, Italia, España. En último lugar, cabe destacar el tratamiento biográfico utilizado por el autor para identificar, no sólo individuos concretos, sino también el itinerario de circulación, recepción y utilización de ideas. Para la historia de las ideas, preocupada por la "esencia” del pensamiento de ciertos intelectuales, la fecha era un dato accesorio, al mismo tiempo que las ideas ajenas a dicha esencia han sido catalogadas como contradicciones. La "apuesta 
biográfica” le permite a Tarcus demostrar que la adopción de las nociones socialistas estuvo ligada a la participación política del colectivo histórico estudiado y no fue mera copia de un modelo. Así, ofrece la posibilidad de estudiar cómo un conjunto de ideas apareció en un primer momento para ser posteriormente reemplazado por otro: no sólo la Joven Generación abandonará los principios socialistas hacia fines de la década de 1840, sino que en el exilio su pensamiento fue moldeándose al calor de la lucha política contra el rosismo, lo que, en última instancia, terminó distanciando a sus miembros, ya no regidos por “dogma” alguno.

La intención del autor de encontrar figuras menores dentro de la intelectualidad rioplatense se cumple, tal vez, para el caso oriental. En cambio, en el análisis porteño se ciñe a las grandes figuras que conformaron la Generación del '37. Ligado a esto, el "descenso de la haute culture a las culturas populares” no es estudiado. ¿Intentó la elite intelectual acercarse a los sectores bajos de la población? A través de los periódicos, la experiencia socialista europea apeló al sector obrero, actor clave en las revoluciones de 1830 y 1848. En el Río de la Plata, por el contrario, no existía una clase trabajadora urbana, poseedora, además, de una cultura escrita. Resulta curioso, pues, que dos de los periódicos destinados a esos sectores, El Grito Arjentino y Muera Rosas!, no sean estudiados. Tarcus insinúa el problema para clausurarlo inmediatamente.

En conclusión, el libro de Tarcus retoma una problemática poco tratada desde las nuevas perspectivas historiográficas de los últimos treinta años. Rompe con la historia de las ideas y su tesis de modelo/influencia y sostiene, en cambio, que la recepción y uso de las nociones socialistas por parte de los jóvenes intelectuales estuvieron anclados a la dinámica política local, tanto en lo relativo a las ideas que profesaron como a las formas asociativas que adoptaron. Asimismo, el libro destaca la problemática adopción de ciertas nociones del programa socialista debido tanto a la presencia de otras corrientes en su pensamiento, como también a sus necesidades políticas específicas que, en muchos casos, llevó a su reformulación hacia concepciones liberales. 